\title{
M. R. Dilts, Demosthenis Orationes. Tomus III, Oxford: Oxford University Press, 2008, pp. 400, ISBN 978-0198721703.
}

This is the third volume (of four) of Mervin Dilts' new Oxford Classical Text of Demosthenes, replacing the previous four-volume set edited by S. H. Butcher (vols. I and II.1) and W. Rennie (vols. II.2 and III) in the earlier years of the last century (1903-1931). Dilts' rate of publication has been brisk: vol. I was published in 2002, and volume IV appeared in 2009. The present volume contains speeches 25-40; it covers the same speeches as Rennie's vol. II.2, together with 25 and 26 which were edited by Butcher in vol. II.1.

The English preface to the volume reprises much material from the preface to vol. I, but is shorter than it and (among other minor changes) omits the sections "Text History in Antiquity" and "Editions", and condenses the section "Principles of this Edition" under the new title "Constitution of the Text", which omits the important subsection "The manuscripts S and AFY". We are therefore left to assume that the same editorial principles are at work in vol. III as were applied in vols. 1 and II, both in the evaluation of the manuscripts (and papyri and testimonia) and in the treatment of hiatus.

The re-editing of Demosthenes is amply justified inter alia by the number of papyrus fragments that have been published in the intervening years (though there are understandably many fewer for this volume than there were for vols. I and II). Dilts has also made a point of scouring later writers of antiquity for quotations of Demosthenes, and included them in a (second) apparatus, placed between the text and the apparatus criticus, of testimonia. These are certainly interesting, and potentially of interest in editing the text, though I wonder -- to the extent that they will have been quoting from memory -- quite how useful their evidence is (in a few places the apparatus criticus is thick with mistaken readings from an ancient author). Dilts, who brings to the task considerable experience as editor both of Aeschines' speeches and of the scholia to Aeschines and Demosthenes, has also re-examined the primary manuscripts, and the text that he has produced is judicious, and a marked improvement on its predecessor. There is a limit, I think, to how far the text of Demosthenes is susceptible of radical re-editing, and Dilts in general pursues a via media: he eschews, for instance, excessive dependence on the oldest ms. S, arguing that differences between it and the other primary mss., AFY, must be considered on a case-by-case basis (vol. I, pp. xvi-xvii). He also steps back from Friedrich Blass's doctrinaire "correction" of hiatus in the mss. of Demosthenes. I noted only one of Dilts' own emendations: in a disputed passage at 25.100. At 36.32 the apparatus criticus implies that the insertion of $\tau \tilde{\omega}$ is also his emendation, but the apparatus criticus to Rennie's text attributes this suggestion (which Rennie does not admit into the text) to "margo Lutetianae" (i.e. a marginal comment in ms. S). 
For all the editorial expertise that Dilts has brought to bear, unfortunately the volume is disfigured by altogether too many typographical errors and other slips. This was identified as a weakness by Michael Edwards in his review of vol. II, which he described as "riddled with typographical and other errors, particularly in the critical apparatus" ( $C R 57,2007,301-2$, at 302$)$. It is disappointing to have to report that almost all the individual deficiencies noted by Edwards are also present in vol. III.

The Preface alone contains: a pair of non-matching brackets (p. v); the misspelling of the title of Kapparis' edition of Dem. 59 as Apollodorus rather than Apollodoros (p. vii n. 9); a wrong subtitle and date of publication for Clavaud's Budé edition of Dem. 60 and 61 (p. vii n. 10; cf. p. viii n. 12 where it is correctly cited); the mangling of MacDowell's surname as MacDoweil, (p. viii n. 12); a comma missing (last line of p. ix); and a wrong breathing ( $\dot{\varepsilon}$ ou $\lambda$ ó $\mu \eta v$, p. x).

In the text itself I noticed the following slips: $\dot{\varepsilon} \mu \mathrm{or}(25.3$, p. 1); $\alpha \tilde{v}(25.18)$;

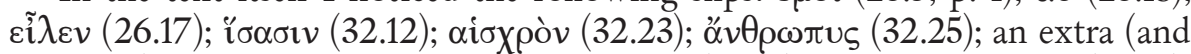

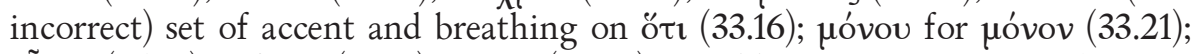

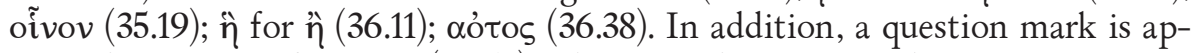
parently missing after <oú> (36.53). There are also occasional inconsistencies in the use of double or single quotation marks in the Greek (generally double, but single at 36.20 and elsewhere; both are used at 37.53 , where in addition one of the marks is misplaced). There are, finally, a number of places where words are broken at the end of a line in ways that will seem unnatural to any reader of

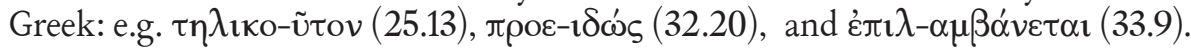

Turning to the apparatus criticus, there are recurring problems with spacing. For example on p. 185 in the second line the words are so squashed together that they are barely legible. In other places the justifying of the text has caused large gaps to open up between words that belong together (e.g. p. 169 on 1. 14; p. 195 on 11. 2-3). In addition, the intermittent addition of "cod." or "codd." before the sigla identifying manuscripts appears to be redundant (e.g. p. 151: "S et cod. Q"; does this differ from "SQ"?). Other miscellaneous errors include the omission

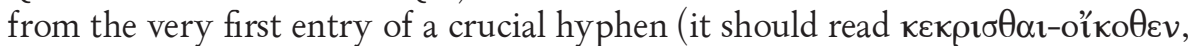

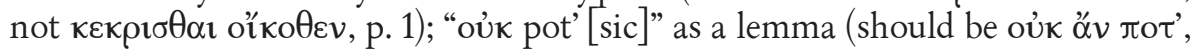
p. 176); inconsistency over whether the editor (Friedrich) Blass is abbreviated "Bl." or named in full. Finally, at 25.28 there is added at the end of a list of ancient authors who support a particular reading "Isidor. Pelus", i.e. the $5^{\text {th }}$-century Christian writer Isodorus of Pelusium. But if Isidorus provides evidence for this reading, he should surely appear in the Apparatus Testimoniorum, which he does not. Moreover, a search of TLG reveals no match for this passage in his writings, and I am led to suppose that this is a phantom reference.

The Compendia Auctorum provides abbreviations for the numerous ancient works that are cited in the Apparatus Testimoniorum. This is very helpful, but there are several inconsistencies between the Compendia and the Apparatus. Already on p. 1 the Apparatus twice abbreviates Aristides, Libri Rhetorici as "Aristid." whereas the Compendia has "Aristid. Rh.” Tiberius, De Figuris Demosthenicis is abbreviated "Tib. Fig." in the Compendia, but "Tib." in the Ap- 
paratus (25.28). Similarly in the Compendia Auctorum Hermogenes, Rhetorica and Ioannes Sardianus, Commentarium in Aphthonii progymnasmata are abbreviated as "Hermog. R." and "Io. Sard. R". respectively (after the name of their editor, Rabe), but in the Apparatus they appear as "Hermog." and "Io. Sard." (e.g. p. 125). Moreover, the Compendia Auctorum is incomplete. That better-known classical authors who are cited in the Apparatus (Pliny, Plutarch, etc.) are omitted from the Compendia is perhaps reasonable (though they could usefully have been included), but there are also no entries for a number of less familiar writers who are cited (with abbreviated forms of their names) in the Apparatus: e.g. "Phryn. Ecl." (p. 3), "Ammon." (p. 20), and "Zonar." (p. 69). None of these is a particularly well known text, and it required a consultation of the TLG for me

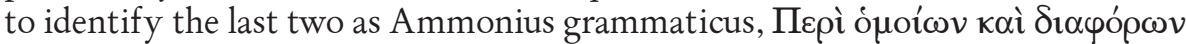
$\lambda \varepsilon \varepsilon_{\varepsilon} \varepsilon v$ and the Lexicon of Pseudo-Zonaras.

There are further problems in the Apparatus Testimoniorum. On p. 73, for

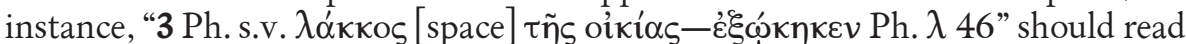

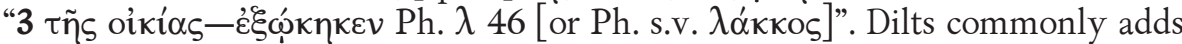
the initial letter(s) of the editor's surname after the citations of a work in the Apparatus, without anywhere explaining this procedure: e.g. (p. 19) "Alex. 3.29.8 Sp.”. The information that this adds is redundant, since the Compendia Auctorum already tells the reader that the edition used for Alexander Rhetor's De Figuris is that of L. Spengel. Moreover, although Sp(engel) and W(alz) appear in the Compendia, the commonly used $\mathrm{R}$ (abe) does not, whereas (potentially confusingly) $\mathrm{R}$ is used as the siglum for one of the codices recentiores.

Something is also amiss with the citation of papyri. In the list of Fragmenta Papyracea on p. 11 there are separate listings first for "P. Berol. 17067" (for 29.59, 30.1-2); and then for "P. Berolin. [sic, and without inventory number] = Archiv 40 (1994) 25-27" (for 30.1). But the relevant article (W. Brashear, "P. Berol. 17067. Demosthenes 29.60: Contra Aphobum; 30.1: Contra Onetorem”, Archiv für Papyrusforschung 40 [1994] 25-27) seems to indicate that these are one and the same papyrus. Nor are papyri consistently cited in the Apparatus Testimoniorum: compare "P. Berol. 17067" (p. 88), "P. Berol. П17067" (p. 90), and even "Membr. Lit. Lond. 125" (p. 21); "PSI XI" and "PSI xi" appear on the same page (p. 43).

Finally, the header for Dem. 36 For Phormion wrongly puts Demosthenes' name in square brackets, indicating that in the editor's opinion the speech is not by Demosthenes. (It is clear from the speech's title on p. 161 that Dilts does in fact accept the communis opinio that this speech is the work of Demosthenes.) And the author's name, $\triangle \mathrm{HMO} \Sigma \mathrm{OENOY} \Sigma$, is omitted for no reason that I can see from the titles of speeches 32 and 38.

Many of these errors are arguably minor in themselves, although it is not unreasonable to expect particular scrupulousness in matters of detail in the editing of a classical text. Cumulatively, however, they are a substantial blemish on what is in other ways a fine edition. This is particularly frustrating since all the same errors were clearly pointed out in at least one review of an earlier volume in the series, and since most of them would have been relatively easy to identify 
and correct. Dilts has an established record as an editor, and OUP a long history of publishing classical texts, but the production of this volume leaves quite a lot to be desired.

Nevertheless, this is clearly now the standard edition of these speeches, and all readers of Demosthenes owe Dilts a debt of gratitude for completing this project.

\author{
JEREMY TREVETT \\ York University \\ jtrevett@yorku.ca
}

